\title{
Population predictors of community health and social service use in Northern Ireland
}

\author{
A $M$ Warnes, G K Armstrong, D Peters
}

\begin{abstract}
Study objective-To investigate the characteristics of elderly populations associated with variations in their use of community health and personal social services and to test the hypotheses that the variations are related to: (a) the age structure of an elderly population; (b) the population's socioeconomic composition, including the level of deprivation; and (c) household or living arrangements.

Design-A common file of 1991 population census and 1994 NHS community trust operational variables was constructed for 67 postcode sectors, with the independent variables describing the age-sex groups to be studied. Clear criteria for the exclusion of "empty" sectors were developed. Relationships using bivariate and multivariate correlation and stepwise multiple regression were explored.
\end{abstract}

Setting-Eastern Health and Social Services Board area, Northern Ireland (Belfast and hinterland).

Participants-Population of statutory pensionable age; in aggregate, younger and older age bands.

Main results-The age structure or mean age of the elderly population had only a weak association with the community health and social service client rate, but there were strong associations with socioeconomic variables, particularly the percentage of those living alone who were without a car and the percentage of pensioner households that included an adult of below pensionable age. Parsimonious multiple regression models accounted for between $46 \%$ and $80 \%$ of the variation in the NHS community trust client rate. Greater explanations were achieved for the young elderly population than for those aged 75+ years and, when the population was divided between young and old age bands, for men than for women.

Conclusions-Community health and so-

Centre for Ageing and Rehabilitation Studies, Community Sciences Centre, Northern General Hospital, Sheffield S5 7AU A $M$ Warnes G K Armstrong D Peters

Correspondence to: Professor A M Warnes.

Accepted for publication January 1997 use if no account is taken of the relative prevalence of need in the youngest or base age group.

( $F$ Epidemiol Community Health 1997;51:722-730)

This paper investigates the factors associated with a person being a client of the "elderly programme" of domiciliary social care services provided by four community health and social service NHS trusts (CHSSTs) in the Eastern Health and Social Services Board (EHSSB) area of Northern Ireland. The research was part of a study of the basis of need for services from which recommendations for a more equitable resource distribution formula are being developed.

Health and social services in Northern Ireland were reorganised in 1973, at which time the personal social services, previously the responsibility of county and borough councils, were amalgamated with the National Health Service (NHS) and came under the Department of Health and Social Services. ${ }^{1}$ Responsibility for planning, administering, and coordinating services was then delegated to four area boards, including the Eastern which is the most populous and covers Belfast, most of County Down, and a small part of Antrim to the south and west of Belfast. Another major review came in 1989, heralded by the two White Papers, Working for Patients (which covered Northern Ireland), and People First (the Province's variant of Caring for People). The subsequent health and social care reforms came into effect in $1993 .^{2}$

The CHSSTs provide an impressive range of personal social and community health services. Some, for chronically disabled persons, are long term and intensive; others, for convalescents, are for a fixed period of diminishing intensity. The services are heterogeneous in other respects, for while most are labour intensive personal services, there is also nonrecurrent expenditure on house adaptations and equipment. The elderly population, therefore, demands and receives diverse domiciliary, day centre, and residential services. The problem for the EHSSB is to identify the population (or area) characteristics that are correlated with the volume and composition of needs, and to find reliable and routinely revisable indices of these characteristics.

The problem is magnified by the diversity of the EHSSB's area. Each of the four trusts has an over-representation of one or more characteristics that are probably associated with high needs for health and social service support. 


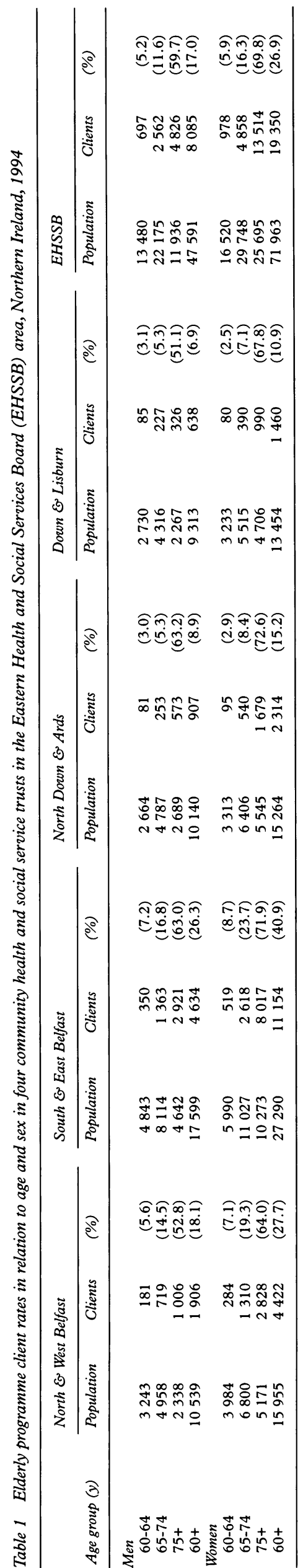

KEY POINTS

- Statutory social care services in the east of Northern Ireland are targeted at those older people who live alone or who are not living with non-pensioners.

- The widespread assumption that morbidity and dependency increase with the average age of an elderly population is not universally true and may distort perceptions of comparative need.

The area includes in Belfast, for example, neighbourhoods with among the most severe levels of inner city deprivation to be found in north west Europe. Not only are material standards of living exceptionally low, but there is overcrowding, a high level of tobacco and alcohol consumption, poor nutrition and sedentary life style, and low levels of knowledge of health services and of self referral on signs and symptoms of disease. In the outer suburbs and satellite towns around Belfast, however, while the material standard of living and longevity are high, the elevated social status is associated with a high proportion of people in advanced old age and of elderly people who live alone, have been childless, or whose children and relatives are not living nearby. For this group, the availability of co-resident spouses and of proximate kin to offer support is low. Then again, in the remote rural areas of low population density, as on the Ards Peninsula, there are many elderly people living far from relatives and from basic services, including general practice surgeries. The inaccessibility of medical and general services may increase their dependency and needs, and may also be associated with above average unit costs of provision.

In December 1994, the CHSSTs recorded 29704 elderly programme clients, of whom nearly 4 in 10 were aged at least 80 years. More than $50 \%$ of the population aged $75+$ years were enrolled as clients (table 1). There was a positive relationship between age and the percentage enrolled for both men and women. In addition, 16437 people were recorded separately as receiving community health services. The principal services delivered in relation to the number of clients were as follows: social work (10 599), occupational therapy (7830), home helps (4685), district nursing and chiropody. Substantial numbers received daily living equipment, help with adaptations to property, community dentistry, community psychiatric services, health visitors, and physiotherapy. There were intricate variations in the patterns of provision among the four trusts. Broadly, the two Belfast trusts had higher rates of provision than the two country trusts, particularly for those under 75 years of age. ${ }^{3}$ There were clear differences in services provided by the two country trusts with occupational therapy usage, for example, being high in North Down \& Ards and low in Down \& Lisburn. Some of these differences may be reporting rather than activity differences. 
Equitable resource allocation among such diverse populations and geographical settings needs to be multifactorial, explicit, widely accepted as rational and "fair", and capable of annual adjustment. The "elderly programme" in $1993 \mathrm{had}$ a budget of approximately $£ 45$ million which was distributed on the basis of the number and age structure of the elderly population, with an age capitation weighting scale of $1: 2: 4$, referring respectively to the age groups 65-74: 75-84: $85+$ years. To date, evidence from operational data and the 1991 census have been collated to show a more appropriate age function of need and utilisation. A revised capitation scale of $1: 2.8: 5$ has been recommended. In addition, a second weighting to reflect variations in the age specific prevalence of long term limiting illness was proposed. The two recommendations were adopted in the resource allocation process for 1995/96.

\section{Aims, hypotheses, and method}

The purpose of the reported analysis was to model the local variation in the community health and social service elderly programme client rate, using variables from the population census to represent the age structure, socioeconomic composition, and household composition. In contrast to many similar studies, the age references of the independent variables wherever possible replicated the age band of the client rate. We searched tenaciously for characteristics that described the age and sex groups of the precise population whose service needs and utilisation were being considered.

The unit of analysis was the postcode sector, viz "neighbourhoods" with a mean population aged $60+$ years of $1774(s=700.1)$. The dependent variable was the rate (or percentage) of the age-sex group who were enrolled clients of the four CHSSTs in December 1994. The count of clients was extracted from the NHS operational database, SOSCARE, maintained by the Directorate of Information Services of the Northern Ireland Health and Personal Services Management Executive. This database uses unique personal identifiers which eliminate double entries for individuals. The record for each client includes a binary indicator of each service received. Each record is updated from many data entry points among the CHSSTs, and when a service is stopped, that fact is explicitly entered on the record. When a person ceases to receive any service, the record is removed to a "former client" file. The denominators for the rates were the age-sex specific population counts from the 1991 census, obtained from the small area statistics files held at the University of Manchester Computing Centre. Separate models were run for the two sexes and for three age bands of older people-the entire pensionable population, those less than 75 years of age, and those above this age. The mean sector population of the smallest group, men aged $75+$ years, was $177(\mathrm{~s}=69.8)$.

The four CHSSTs in eastern Northern Ireland returned contrasting client rates (table 1). These variations arose from policy, ex- penditure, and reporting differences. No evidence was found, however, of significant or systematic local or "patch" variations in policy or reporting within a CHSST. It was therefore assumed that differences in the age specific prevalence of enrolled clients in relation to local area within a trust reliably indicated differences in the relative need for the available services, and argued that comparisons in relative needs between postcode sectors in different trusts could be made when the "trust policy and reporting effect" was removed by standardisation. The client rates for each postcode sector $\left(\mathrm{CR}_{\mathrm{PCS}}\right)$ were accordingly divided by the rate for its trust $\left(\mathrm{CR}_{\mathrm{CHSST}}\right)$. The modelled dependent variable $\left(\mathrm{CR}_{\mathrm{REL}}\right)$ was therefore the age-sex specific client rate for the postcode sectors expressed as a ratio of the overall trust rate divided by the EHSSB rate $\left(\mathrm{CR}_{\mathrm{EHSSB}}\right)$. This was given by the formula $C_{\mathrm{REL}}=\mathrm{CR}_{\mathrm{PCS}} \times$ $\mathrm{CR}_{\mathrm{EHSSB}} \div \mathrm{CR}_{\text {CHSST }}$.

The independent variables representing the characteristics of older people living in the community (not in institutions) were drawn from the 1991 population census of Northern Ireland. ${ }^{4}$ They were analysed for 67 postcode sectors. Although there were 84 postcode sectors in the EHSSB, 12 were excluded because they had fewer than 12 CHSST clients (two are within Belfast city centre and had tiny residential populations), and five could not be attributed to a single trust.

The analysis examined the hypothesis that across the 67 areas the relative client rate for elderly programme services was associated with three constructs:

- The age structure of the elderly population,

- Their socioeconomic status, including the prevalence of material and housing deprivation, and

- The composition of households containing pensioners (sometimes known as the living arrangement).

Each construct was represented by several census variables.

Census questions are extensively field tested and debated before adoption but their content or validity is not often explicitly investigated. Some, such as living alone, hardly need elucidation; others, such as the possession of educational qualifications, are descriptively self evident but most valuable as surrogates or indices of other characteristics. There is insufficient space for a detailed critique of each variable. The means and SDs are, however, presented among the tabulated results. These enable a first assessment of the confidence which can be placed in the various results. Fuller discussion of specific variables is given at appropriate points in the discussion section.

\section{Age structure of the older population and} the relative client rates

The age structure was represented by both the estimated mean age of the population in the age band and the percentages of that age band in each constituent five year age group. The age distribution of the female population aged $60+$ years was, for example, described by seven percentages including one for the open ended 90+ years category (being six variates as they sum to 
Table 2 Correlations of community health and social services NHS trust client rates in 67 postcode sectors with the age structure of the elderly population; Eastern Health and Social Services Board area of Northern Ireland, 1994t

\begin{tabular}{|c|c|c|c|c|c|c|c|c|}
\hline \multirow[b]{2}{*}{ Age group (y) } & \multicolumn{4}{|l|}{ Men } & \multicolumn{4}{|l|}{ Women } \\
\hline & $65+y$ & $65-74 y$ & $75+y$ & & $60+y$ & & $60-74 y$ & $75+y$ \\
\hline \multicolumn{9}{|c|}{ (A) Mean (SD) for age group shares (\%) and mean age } \\
\hline $60-64$ & & & & & 24.2 & $(3.6)$ & $35.9(3.5)$ & \\
\hline $65-69$ & $(3.9)$ & 57.3 & & & 23.5 & $(2.0)$ & $35.0 \quad(1.9)$ & \\
\hline $70-74$ & $(1.9)$ & 42.7 & & & 19.5 & $(1.7)$ & $29.1(2.9)$ & \\
\hline $75-79$ & $(2.6)$ & & 57.3 & $(5.4)$ & 16.1 & $(2.2)$ & & $49.2(3.5)$ \\
\hline $80-84$ & $(2.1)$ & & 29.9 & $(4.3)$ & 10.5 & $(2.0)$ & & $32.0(3.2)$ \\
\hline $85-89$ & (1.1) & & 10.2 & $(2.9)$ & 4.7 & $(1.1)$ & & $14.1(2.3)$ \\
\hline $90+$ & $(0.4)$ & & 2.6 & $(1.2)$ & 1.6 & $(0.6)$ & & $4.8(1.6)$ \\
\hline Mean $\ddagger$ & $(0.7)$ & 69.2 & 80.1 & $(0.5)$ & 71.9 & (1.1) & $66.7 \quad(0.3)$ & $81.3(0.6)$ \\
\hline \multicolumn{9}{|c|}{ (B) Correlation coefficients $\$$ between client rate and age group shares (\%) and mean age } \\
\hline $60-64$ & & & & & -0.22 & & -0.10 & \\
\hline $65-69$ & 0.09 & $0.32^{\star \star}$ & & & -0.04 & & 0.23 & \\
\hline $70-74$ & $-0.26^{\star}$ & -0.16 & & & -0.06 & & 0.01 & \\
\hline $75-79$ & $0.33^{\star \star}$ & & $0.24^{\star}$ & & $0.09^{1}$ & & & 0.02 \\
\hline $80-84$ & -0.08 & & $-0.42^{\star \star \star}$ & & 0.20 & & & 0.04 \\
\hline $85-89$ & 0.03 & & $-0.10^{1}$ & & $0.08^{2}$ & & & -0.16 \\
\hline $90+$ & 0.08 & & -0.14 & & $0.04^{2}$ & & & -0.10 \\
\hline Multiple $\mathrm{R}^{2}$ & 0.28 & 0.11 & 0.21 & & 0.12 & & 0.06 & 0.04 \\
\hline Mean & -0.06 & $-0.29^{\star}$ & $-0.27^{\star}$ & & 0.16 & & 0.06 & -0.11 \\
\hline
\end{tabular}

tThe age structure of each age band is represented by both the estimated mean age and the share of the age band in its constituent five-year age groups. $\ddagger$ Mean (SD) of the postcode sector mean ages in years. $§$ Pearson product moment linear correlation coefficients between the standardised SOSCARE client rates and these measures. The $\mathrm{R}^{2}$ are presented only as comparative descriptive measures. Two tailed significance of $r_{x y}$ on $H_{0}:{ }^{\star} p<0.05,{ }^{\star \star} p<0.01$ and ${ }^{\star \star \star} p<0.001$. Transformations towards a normal distribution: 1 - square root. 2 - logarithm to base 10.

$100 \%)$. The age group percentages enabled detection of associations between the client rates and the relative share of the postcode sector populations at the youngest or oldest ages of the various age bands (table 2). Dependent and explanatory variables were checked for non-normality using scatter plots and Lilliefor's test.

It was expected that areas with an above average share of older people (in the age range) would have a higher prevalence of morbidity, and therefore a higher need of domiciliary services and, consequently, a higher client rate. The results, however, generally showed very low associations. Only among men were there significant bivariate correlations between the client rates and the share in any of the five year age groups or the mean ages. The multiple coefficients of determination $\left(R^{2}\right)$ for the sets of age group percentages are presented as comparative descriptive statistics. They range from 0.0 to $0.3-\mathrm{ie}$, in no case was more than $30 \%$ of the variation in the client rate associated with the age distribution of elderly people, and for most age-sex ranges the association was lower.
The strongest correlation with the mean age, for younger men, produced an $\mathrm{R}^{2}$ of just 0.08 . The age structure of the older population, therefore, had only a weak association with the allocation and delivery of the CHSST social care services.

The lack of association among women was exceptional and was not expected. The two arrays of correlation coefficients for the $75+$ years age group and the significant negative associations with the male mean ages are, however, intriguing in another respect. They suggest an inverse relation between the client rate and the share of the older population in the oldest quinquennial divisions, and a positive relation with the share in the youngest quinquennial groups.

\section{Social class, deprivation, and the client rate}

Most research on status and health variations among elderly people refers at some point to the concepts and qualities of social class and deprivation..$^{5-10}$ These overlapping concepts are complex and elusive, and may be approximated

Table 3 Correlations of community health and social services NHS trust relative client rates with social class and deprivation variables: 67 postcode sectors, Eastern Health and Social Services Board area of Northern Ireland, 1994

\begin{tabular}{|c|c|c|c|c|c|c|}
\hline \multirow[b]{2}{*}{ Variables } & \multicolumn{3}{|l|}{ Men } & \multicolumn{3}{|l|}{ Women } \\
\hline & $65+$ & $65-74 t$ & $75+$ & $60+$ & $60-74$ & $75+$ \\
\hline \multicolumn{7}{|c|}{ A Mean (SD) for age group percentage (or as footnoted) } \\
\hline Households in owner occupation $\ddagger$ & $59.9(18.9)$ & $62.6(18.8)$ & $54.6(19.6)$ & $59.9(18.9)$ & $62.6(18.8)$ & $54.6(19.6)$ \\
\hline With degree/diploma & $12.9(10.8)$ & - & - & $6.9(5.9)$ & $\ldots$ & $\ldots$ \\
\hline Living alone $\$$, without cart & $64.4(17.5)$ & $60.7(18.5)$ & $69.5(18.2)$ & $82.2(12.1)$ & $75.6(16.2)$ & $90.1(8.1)$ \\
\hline Living alone $\oint$, lacking wcts & $7.0(6.3)$ & $6.9(7.0)$ & $7.6(7.8)$ & $4.0(3.8)$ & $2.9(2.9)$ & $5.3(5.3)$ \\
\hline Living alone $\widehat{S}$, without central heating $\dagger$ & $31.5(13.3)$ & $30.5(15.0)$ & $33.4(14.2)$ & $25.6(10.5)$ & $21.3(9.4)$ & $30.5(12.7)$ \\
\hline \multicolumn{7}{|c|}{$B$ Pearson product moment linear correlation coefficients with the client rate } \\
\hline Households in owner occupation $\ddagger$ & $-0.59^{\star \star \star}$ & $-0.73^{\star \star \star}$ & $-0.50^{\star \star \star}$ & $-0.59^{\star \star \star}$ & $-0.79^{\star \star \star}$ & $-0.45^{\star \star \star}$ \\
\hline With degree/diploma & $-0.39^{\star \star} 60$ & $-0.49 \star \star \star 8 S$ & $-0.26 \star 80$ & $-0.50^{\star \star \star} \neq \neq$ & $-0.65^{\star \star \star} \ddagger$ & $-0.42^{\star \star \star} \neq \ddagger$ \\
\hline Living alone $\widehat{\oint}$, without cart & $0.63^{\star \star \star}$ & $0.74^{\star \star \star}$ & $0.51 \star \star \star$ & $0.63^{\star \star \star}$ & $0.75^{\star \star \star}$ & $0.49^{\star \star \star}$ \\
\hline Lving alone $\int$, lacking wcts & $-0.25^{\star}+\dagger$ & $-0.23+\dagger$ & $-0.30^{\star}$ & $-0.03 \ddagger \ddagger$ & $0.16 \neq \ddagger$ & $-0.17+t$ \\
\hline Living alone $\int$, without central heating $\dagger$ & $-0.34^{\star \star}+\dagger$ & $-0.44^{\star \star \star}$ & -0.24 & -0.08 & 0.01 & -0.21 \\
\hline Multiple $\mathrm{R}^{2}$ & 0.52 & 0.74 & 0.65 & 0.50 & 0.66 & 0.44 \\
\hline
\end{tabular}

†Percentage of the age-sex group population. $\ddagger$ Percentage of household heads of the given age-sex group. $\$$ Percentage of persons in the age-sex group living alone. PPercentage of the pensionable-age population of that sex. sWithout or sharing use of bath/shower and/or inside wc. Two tailed significance of $r_{x y}$ on $H_{0}:{ }^{\star} p<0.05,{ }^{\star \star} p<0.01$ and ${ }^{\star \star \star} p<0.001$. Transformations to normality: $\dagger+$ square root, 扭cube root, and $\iint \log _{10}$. The $\mathrm{R}^{2}$ are presented only as comparative descriptive measures. 
Table 4 Correlations of community health and social services NHS trust client rates with marital status and living arrangements: Eastern Health and Social Services Board area of Northern Ireland, 1994

\begin{tabular}{|c|c|c|c|c|c|c|}
\hline \multirow[b]{2}{*}{ Household or marital status } & \multicolumn{3}{|c|}{ Men or (both sexes) } & \multicolumn{3}{|l|}{ Women } \\
\hline & $65+$ & $65-74$ & $75+$ & $60+$ & $60-74$ & $75+$ \\
\hline \multicolumn{7}{|c|}{ A. Mean (SD) for the age-sex group percentage (or as footnoted) } \\
\hline$\%$ living alonet & $20.4(7.1)$ & $17.7(7.7)$ & $25.5(7.0)$ & $35.9(7.1)$ & $18.3(2.9)$ & $46.4(9.2)$ \\
\hline$\%$ single, widowed, or divorced $\dagger$ & $32.0(9.6)$ & $26.3(10.6)$ & $42.7(9.9)$ & $59.4(6.8)$ & $47.4(7.1)$ & $81.2(4.6)$ \\
\hline $\begin{array}{l}\% \text { in } 2+\text { pensioner households } \\
\% \text { in } 1+\text { pensioner(s) with } 1+\text { non-pensioner(s) }\end{array}$ & $35.9(7.2) \ddagger$ & $37.7(8.2) \S$ & $33.4(6.3) 9 t \dagger$ & - & - & - \\
\hline households & $33.2(7.0 \ddagger \ddagger) \dagger \dagger$ & - & - & - & - & - \\
\hline \multicolumn{7}{|c|}{ B. Pearson product moment linear correlation coefficients with the client rate } \\
\hline$\%$ living alonet & $0.50(\mathrm{~S})^{\star \star \star}$ & $0.67 \star \star \star \star 6 S$ & $0.40^{\star \star \star \star} 60$ & $0.68^{\star \star \star}$ & $0.63^{\star \star \star}$ & $0.57^{\star \star \star}$ \\
\hline$\%$ single, widowed, or divorced $\dagger$ & $0.40^{\star \star \star \star \Delta} 8 \int$ & $0.56^{\star \star \star \pi \int 8}$ & $0.04 \Omega 8$ & $0.42^{\star \star \star}$ & $0.59^{\star \star \star}$ & 0.13 \\
\hline $\begin{array}{l}\% \text { in } 2+\text { pensioner households } \\
\% \text { in } 1+\text { pensioner(s) with } 1+\text { non-pensioner(s) }\end{array}$ & $-0.59 \star \star$ & $-0.71^{\star \star \star}$ & $-0.40^{\star \star \star}$ & $-0.58^{\star \star \star}$ & $-0.67^{\star \star \star}$ & $-0.41^{\star \star \star}$ \\
\hline households & $-0.44^{\star \star \star}$ & $-0.36^{\star \star}$ & $-0.34^{\star \star}$ & $-0.53^{\star \star \star}$ & $-0.36 \star \star$ & $-0.42^{\star \star \star}$ \\
\hline Multiple $\mathrm{R}^{2}$ & 0.47 & 0.60 & 0.25 & 0.53 & 0.50 & 0.36 \\
\hline
\end{tabular}

†Percentage of the age-sex group population. $\ddagger$ Two or more person households as a percentage of households containing pensioners. $₫$ Households including a person of pensionable but less than 75 years of age and with two or more pensioners as a percentage of households including a person of pensionable but less than 75 years of age and no non-pensioners. ๆHouseholds that contain two or more persons of $75+$ years of age as a percentage of households containing persons aged $75+$ years and no non-pensioners. + Both sexes. $¥+$ Percentage of households containing pensioners with $1+$ pensioners and $1+$ non-pensioners. $\$ \delta T$ ransformation to normality: $\log _{10}$. Two tailed significance of $r_{x y}$ on $H_{0}:{ }^{\star} p<0.05,{ }^{\star \star} p<0.01$ and ${ }^{\star \star \star} p<0.001$. S=Spearman's rank correlation coefficient. The $R^{2}$ are presented only as comparative descriptive measures.

by innumerable measures of income, education, occupation, housing, and lifestyle. Many health service studies use a questionable methodological device-they index the status of retired people by measures of the economic activity rate, occupations, and housing standards of the working age population. Some indices even use perinatal mortality or low birth weight as an index of deprivation among retired people. The device is not nonsensical, for there are "ecological" associations. For example, areas of high income working age people will tend to have high income retired people and vice versa. But it removes analysis from a focus on the characteristics of elderly people, for which the current analysis strives. The device is also pragmatic, for many fewer variables are available to describe the elderly than the working age or general populations, and several widely useful social indicators, such as current occupation or means of travel to work, do not apply to retired people. This problem of unavailability of data has, however, lessened recently, for the 1991 census considerably extended the coding and tabulation of variables specifically for the older population and its constituent age groups.

The 1991 Northern Ireland census provides social variables-educational qualifications, housing types, and car ownership-to describe male and female age groups of the elderly population in relation to postcode sectors. The available variables are far from ideal, however, as no information is available on the standard of living in childhood, years of education, last "major" occupation, or the value of a house or the monthly rent. The construction of each variable is indicated by the labelling and footnotes of table 3 .

Much higher correlations are found with the socioeconomic variables than the age structure variables, with $R^{2}$ ranging from $0.44-0.74$. In other words, depending on the age-sex range, between half and three quarters of the variation in the CHSST relative client rate was accounted for by the included socioeconomic measures. Their influence was stronger among the young than the old-elderly population. In the all-pensioner population, there were few differences between men and women. For the narrower age bands, while the individual male correlations were generally no higher than the female, the aggregate $R^{2}$ values were higher. Two variables vied for the strongest influence on the CHSST relative client rate-the percentage of households in a postcode sector in owner occupation (which had a negative association) and the percentage of those living alone who had a car (which had a negative association and accounted for 0.55 of the variation among those aged $65-74$ years).

The housing tenure variable, a familiar indicator of social status and income, is age referenced to the head of the household. The car ownership variable is specified for each age-sex group. Its association with the clien rate was least for the $75+$ years population bu nevertheless accounted for $25 \%$ of the variation and, perhaps surprisingly, its explanatory power was the same for men and women. As a relatively unfamiliar index variable, its validity will be challenged. The variation in the rate of car ownership among elderly people who live alone has been examined carefully in Great Britain as well as in Northern Ireland. The distinctive value of the measure is not so much its overt description of car availability but rathe the fact that it is influenced by income (positively), frailty, and ill health (negatively) and, less obviously, the socioeconomic status of an individual throughout life (positively). ${ }^{1}$ People of low socioeconomic status learned to drive and acquired cars much later in life than high status individuals, and this applied to men and to women. The prevalence of car ownership in today's older cohorts varies therefore in relation to educational and occupational histories and these variations have become stronger than the urban-rural dimension in car ownership.

The housing amenity variables had virtually no association with the relative client rate for women, but significant low correlations were produced by the male distributions. There were negative relationships with the absence of central heating or of exclusive access to 
lavatory, the inverse of a "needs based" expectation. The tenure which generally has the poorest amenities is "renting furnished from private landlords". Few older people, however, live in this sort of accommodation. The finding is more likely to indicate a raised likelihood among men of receiving services when they live in public sector housing, for the physical amenity standards of its modern stock are high.

\section{Living arrangements and the client rate}

The census gives only living alone, living with non-pensioners, and marital status as household composition and living arrangements variables for the older age groups of people living in the community. Unfortunately, nothing on kin relationships within or beyond the household is available (not even whether two pensioners in a household are married). The variable definitions and the correlations with the relative client rate are presented in table 4 . The associations were higher than with the age structure but lower than with the social class measures $\left(R^{2}=0.25-0.60\right)$. The strongest association was for the younger age range of men, and the weakest for men aged $75+$ years. One variable consistently produced the strongest association. This was the percentage of the age-sex group who live alone, and it was positively associated with the relative client rate. For the aggregate elderly female population and among young elderly men, this variable accounted for 0.45 of the variation among the 67 areas.

Other variables in this group produced relatively strong correlations. The variable representing the share living in households of two or more pensioners was intricate to calculate. While it is possible to produce the required age specific variables, no differentiation in relation to sex is offered in the census tabulations. There are subtle changes in the denominator among the three variables (table 4, footnotes $2-4)$. Moderate negative correlations with the relative client rate in the range -0.40 to -0.71 were produced, the associations again being highest for the young age band. The percentage living with non-pensioners generated correlations in the range $r=-0.34$ to -0.53 . If this relationship is seen as an awkward representation of the tendency for social care services to be delivered to older people who live alone and not to others, further reflection suggests that it is more discriminating and does not entirely replicate the variation associated with lone households. The tendency is for services not to be delivered to older people who live with nonpensionable adults, and for them to be delivered to older people when they are living alone, in couples or (as rarely) larger pensioner households.

The most inconsistent correlations with the relative client rate in this group were those of the percentage of the age-sex group who were single, widowed, or divorced (or, the complement, married). In the younger age range, more than one-third of the variation was "explained": in the older age range, virtually none. The relationship is that the higher the married percentage, the lower the client rate. In the current cohort of young elderly people, the principal control on the married rate is the bereavement of spouses. A high population prevalence of early bereavements indicates relatively high or "premature" mortality. This is likely to be associated with relatively high morbidity and dependency. What is at first surprising is that the relationship virtually disappears among people aged $75+$ years, but a high proportion of women in this age group were widowed and the variation among the 67 districts was exceptionally low (table 4).

\section{Pooled stepwise regression models}

To identify which combination of variables from the three constructs best predicted the client rate in each postcode sector, all independent variables were entered in multiple regression analysis. The fitting procedure was ordinary least squares linear multiple regression using the SPSS for Windows software. ${ }^{12}$ The reported analyses employed the "backward elimination" procedure. This starts with the full equation of all variables and first excludes the "weakest". After re-calibrating the reduced equation, it then iteratively excludes second, third, and further variables that contribute insignificant amounts to the variation. The procedure stops when the least "powerful" of the remaining variables does associate with a significant proportion of the variance. The criterion for excluding a variable was that the $t$ value of the regression coefficient was significantly different from zero at a probability of 0.05 . Models for the different age ranges and for each sex are presented.

Interesting equations of moderate explanatory power were produced. The explained variance $\left(R^{2}\right)$ was in no case less than 0.46 but highest for the younger age range (table 5). One independent variable was always the strongest influence, as judged by the $t$ values of the regression coefficients. It was the percentage of those living-alone who were without a car, which positively associated with the client rate. One interpretation is that this variable best summarises the associations among a local population's socioeconomic status (or material advantage or deprivation), morbidity, and dependency and its receipt of community health services. The variable deserves widespread critical attention and is clearly a candidate for inclusion in deprivation and social status indexes for older people.

One other variable appeared in all six models and was always the second most influential. It was the percentage of pensioner headed households which included at least one nonpensioner. This was negatively associated with the client rate. As suggested earlier, a negative association with "households including a nonpensioner" implies a positive relationship of the client rate with all other living arrangements, including both married couple and single pensioner households. The relationship reminds us, and partly demonstrates, that there are complex associations between an older person's age and their marital status, living arrangements, dependency, and need for services. It is not widely appreciated, for example, 
Table 5 Population characteristics associated with CHSST client rates: 67 postcode sectors, Eastern Health and Social Services Board area of Northern Ireland, 1994

\begin{tabular}{|c|c|c|c|c|c|c|}
\hline \multirow[b]{2}{*}{ Independent variables } & \multicolumn{3}{|l|}{ Men } & \multicolumn{3}{|l|}{ Women } \\
\hline & $65+$ & $65-74$ & $75+$ & $60+$ & $60-74$ & $75+$ \\
\hline \multicolumn{7}{|l|}{ Age structure (y) } \\
\hline$\%$ aged $90+$ & & $\dagger$ & & & $t$ & \\
\hline$\%$ aged $85-90$ & & $\dot{t}$ & & $-2.08^{\star}$ & $t$ & $-2.21^{\star}$ \\
\hline$\%$ aged $80-84$ & & $t$ & $-2.28^{\star}$ & & $t$ & \\
\hline$\%$ aged $75-79$ & & $t$ & & & & \\
\hline$\%$ aged $70-74$ & & & $t$ & $-2.58^{\star}$ & $-2.76^{\star}$ & $t$ \\
\hline$\%$ aged $65-69$ & & & t & & & 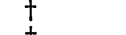 \\
\hline$\%$ aged $60-64$ & $\dagger$ & & $\dagger$ & & & $\dagger$ \\
\hline \multicolumn{7}{|l|}{ Social composition and deprivation } \\
\hline $\begin{array}{l}\text { Alone, } \% \text { without car } \\
\text { Alone, } \% \text { no inside wc }\end{array}$ & $5.40^{\star \star \star \star}$ & $4.99 \star \star \star \star$ & $\begin{array}{l}4.58^{\star \star \star \star} \\
-2.33^{\star}\end{array}$ & $6.93^{\star \star \star \star}$ & $5.24^{\star \star \star \star}$ & $\begin{array}{l}5.05^{\star \star \star \star} \\
-2.27^{\star}\end{array}$ \\
\hline Alone, \% no central heating & $-2.84^{\star \star}$ & & & & & \\
\hline \multicolumn{7}{|l|}{ Household and living arrangement } \\
\hline $\begin{array}{l}\% \text { living with non-pensioners } \\
\% \text { in } 2+\text { pensioner households }\end{array}$ & $-3.47^{\star \star \star}$ & $\begin{array}{l}-2.61^{\star \star} \\
2.52^{\star}\end{array}$ & $-3.89 \star \star \star$ & $-5.88^{\star \star \star \star}$ & $-3.63^{\star \star \star}$ & $-4.24^{\star \star \star}$ \\
\hline$\%$ single, widowed $\&$ divorced & $3.74^{\star \star \star}$ & & & & $2.38^{\star}$ & \\
\hline Constant & 0.61 & $-1.85^{\star \star \star \star}$ & $2.34^{\star}$ & $2.72^{\star \star}$ & -0.94 & $-3.66^{\star \star \star}$ \\
\hline Adjusted $\mathrm{R}^{2}$ & 0.73 & 0.80 & 0.67 & 0.63 & 0.66 & 0.46 \\
\hline Two variable equation ${ }^{1} R^{2}$ & 0.58 & 0.63 & 0.26 & 0.55 & 0.56 & 0.36 \\
\hline$\%$ of "full" $\mathrm{R}^{2}$ & 79 & 79 & 39 & 87 & 85 & 78 \\
\hline
\end{tabular}

The table shows $t$ values and significance for inclusion in backward-elimination ordinary least squares estimation multiple regression equations. For the construction of all variables, see the footnotes to tables 2-4. 1. See text. †Variable not employed in this model. The adjusted $\mathrm{R}^{2}$ slightly reduces the "crude" $\mathrm{R}^{2}$ as a function of the number of included variables. Two tailed significance of $t$ values on $\mathrm{H}_{0}:^{\star} \mathrm{p} \leqslant 0.05,{ }^{\star \star} \mathrm{p} \leqslant 0.01,{ }^{\star \star \star} \mathrm{p} \leqslant 0.001$, and ${ }^{\star \star \star \star} \mathrm{p} \leqslant 0.0001$

that in the older population the relationship between age and the propensity to live with a child is "U" shaped. A relatively high proportion of people in their early 60 s live with a child because their children have not yet left home (or have returned). The proportion is also high in advanced old age, as widowed individuals join their children's households. ${ }^{13}{ }^{14}$ In both sets of circumstances, for a given level of dependence, a person is less likely to need or to be allocated statutory support, because "informal" carers are available and are often able or assumed to be able to provide support.

A poor housing amenity variable was included in two of the male models but in only the $75+$ years model for women. Age structure variables were included in all female models and the $75+$ years male model but generally had the least importance. In no model was the mean age included. The dominant finding was that car ownership among those who lived alone and the older person's living arrangement were the most consistent indicators of a local elderly population's propensity to receive formal domiciliary service support. To establish the "index power" of these two variables, they were entered without others into further regression equations. As the lowest rows of table 5 show, the reduced equations capture four fifths or more of the explained variance of

Table 6 The association between community health and social services NHS trust relative client rates $(y)$ and the 1991 prevalence of long term limiting illness $(x), 67$ post code sectors, Eastern Health and Social Services Board area of Northern Ireland, 1994

\begin{tabular}{|c|c|c|c|c|c|c|}
\hline \multirow[b]{2}{*}{ Long term limiting illness } & \multicolumn{3}{|l|}{ Men } & \multicolumn{3}{|l|}{ Women } \\
\hline & $65+$ & $65-74$ & $75+$ & $60+$ & $60-74$ & $75+$ \\
\hline Mean $(\mathbf{x})$ & 37.1 & 33.1 & 41.3 & 34.1 & 28.3 & 45.3 \\
\hline (SD) & (5.7) & (6.5) & (6.9) & (6.6) & (6.4) & (9.3) \\
\hline Coefficient of variation & 0.15 & 0.20 & 0.17 & 0.19 & 0.23 & 0.21 \\
\hline $\mathrm{r}_{\mathrm{xy}}$ & $0.50^{\star \star \star}$ & $0.69^{\star \star \star}$ & 0.24 & $0.61^{\star \star \star}$ & $0.79^{\star \star \star}$ & $0.40^{\star \star}$ \\
\hline $\mathbf{R}_{\mathrm{xy}}^{2}$ & 0.25 & 0.48 & 0.06 & 0.37 & 0.62 & 0.16 \\
\hline
\end{tabular}

Long term limiting illness is the self (or surrogate) report collected by the 1991 population census of Northern Ireland. Separate variables of prevalence are calculated specific to each age-sex group. Two tailed significance of $\mathrm{r}_{\mathrm{xy}}$ on $\mathrm{H}_{0}:{ }^{\star \star} \mathrm{p} \leqslant 0.01,{ }^{\star \star \star} \mathrm{p} \leqslant 0.001$. all but one of the full equations, the exception being for older males. Neither this analysis nor the identified variables have therefore solved the perennial limitation of predictive models in this field, that they are more successful at accounting for variations in the health and dependency of the young elderly population than for those in advanced old age.

\section{Association with limiting long term illness}

The association between the relative social care client rate and the prevalence of self declared or surrogate declared limiting long term illness (the 1991 census variable) was also examined for each age-sex group (table 6). ${ }^{15}$ The correlations were lower than anticipated. In the aggregate elderly population only $25 \%$ and $37 \%$ of the variation in the male and female client rates respectively were "explained" by the illness variable. Interestingly, however, the explanations were considerably higher in the younger age range, especially in women, with $62 \%$ accounted for. The complementary finding was that among the population aged $75+$ years there were only weak associations between limiting long term illness and the provision of statutory domiciliary care. In men aged $75+$ years, the association was statistically insignificant and only $6 \%$ of the variation was explained.

Given the pattern of relatively strong associations for young elderly people and weak associations for the older, the behaviour of the limiting illness variable in the multiple regressions of the CHSST client rate was surprising. In the male models, when limiting illness was entered with all the previously considered independent variables, it was not selected and the regression equations were unchanged. The association with the limiting illness variable seems to be represented by the socioeconomic status and living arrangement variables. In the three female regression analyses, however 
Table 7 Population characteristics associated with community health and social services NHS trust client rates: women, 67 postcode sectors, Eastern Health and social Services Board area of Northern Ireland, 1994

\begin{tabular}{|c|c|c|c|}
\hline Independent variables & $60+y$ & $60-74 y$ & $75+y$ \\
\hline \multicolumn{4}{|l|}{ Age structure (y) } \\
\hline$\%$ aged $90+$ & $2.75^{\star}$ & $t$ & \\
\hline$\%$ aged $85-90$ & $-2.08^{\star}$ & $t$ & \\
\hline$\%$ aged $80-84$ & & $t$ & \\
\hline$\%$ aged $75-79$ & $-2.60^{\star \star}$ & $t$ & \\
\hline$\%$ aged $70-74$ & & $-2.53^{\star}$ & $t$ \\
\hline$\%$ aged $65-69$ & & & $t$ \\
\hline$\%$ aged $60-64$ & & & $t$ \\
\hline \multicolumn{4}{|l|}{ Social composition and deprivation } \\
\hline$\%$ owner occupiers & $2.42^{\star \star}$ & & \\
\hline alone, $\%$ without car & & & $2.55^{\star \star}$ \\
\hline alone, $\%$ no inside wc & $-2.03^{\star}$ & & $-2.75^{\star \star}$ \\
\hline \multicolumn{4}{|l|}{ Household and living arrangement } \\
\hline$\%$ living with pensioner & $-2.54^{\star \star}$ & & \\
\hline $\begin{array}{l}\% \text { living with non-pensioner } \\
\% \text { single, widowed \& divorced }\end{array}$ & $-3.75^{\star \star \star}$ & $\begin{array}{l}-3.37^{\star \star} \\
2.26^{\star}\end{array}$ & $-4.46^{\star \star \star \star}$ \\
\hline Limiting long term illness & $4.77^{\star \star \star \star}$ & $6.21^{\star \star \star \star}$ & $2.74^{\star}$ \\
\hline Constant & $2.60^{\star \star}$ & 0.78 & $-2.04^{\star}$ \\
\hline Adjusted $R^{2}$ & 0.71 & 0.69 & 0.48 \\
\hline
\end{tabular}

$t$ values and significance of the regression coefficients of the variables included in backward-removal stepwise ordinary least-square estimation multiple regression equations. For the construction of all variables, see the footnotes to tables $2-4$ and 6 . $†$ Variable not employed in this model. Two tailed significance of $t$ values on $\mathrm{H}_{0}:{ }^{\star} \mathrm{p} \leqslant 0.05$, ${ }^{\star \star} \mathrm{p} \leqslant 0.01,{ }^{\star \star \star} \mathrm{p} \leqslant 0.001$ and $\star \star \star \star p ~ \leqslant 0.0001$.

limiting long term illness was included, although in two with no gain in the overall explanation (table 7). Its strongest presence was in the model for the young age range: this is consistent with the pattern of bivariate correlations. The change from the earlier model (table 5) is readily seen, with the illness variable substituting for the "no car" measure, while the explanation contributed by the living arrangement measures increased. Similarly, in the model for females aged $75+$ years, the illness variable entered, displaced the age structure variable, and weakened the contribution of the socioeconomic measures, while the contribution of the living arrangement measure strengthened (table 5). Finally, in the model for all women of pensionable age, the effect of the illness variable on the regression was substantial and disruptive. This model is an inelegant function of eight significant independent variables. Slight alterations to the exclusion criteria or to the tolerance of covariation alter the composition of this unstable equation.

This examination of the "added" contribution of the limiting long term illness variable suggests that for each age-sex group its variation replicates that of the socioeconomic status variables (most clearly the car ownership measure). In men, the illness measure was consistently secondary to the socioeconomic status indicators and in no case was it included in the regression equations. In women, however, the illness measure was included at the expense of the socioeconomic status measures, while the explanation contributed by the living arrangement variables (specifically, the percentage of older people who lived with non-pensioners) was retained and was robust.

\section{Discussion}

In the Eastern Health Board area of Northern Ireland, around $60 \%$ of the variation among local elderly populations in their enrolment for statutory domiciliary social care services can be predicted by readily available census measures.
The proportion is a little more for the young age group, a little less for the older. Socioeconomic status and living arrangement variables were the most influential, but the associations with age structure were weak. One social class variable, the percentage living alone who are without a car (which is probably associated inversely with income and socioeconomic status), was a particularly strong predictor of being a CHSST client. We conclude that services are being targeted towards the lower income groups. The variable which played the second strongest role was the share of the agesex group who lived with one or more non-pensioners. Other things being equal, people in these households had a reduced likelihood of receiving CHSST services. This relation was strongest for the entire age range of elderly people, was much weaker for the young and old age bands of men, but remained strong in women aged $75+$ years.

The most surprising finding of these analyses was the lack of association between the age structure (or mean age) of an older population and the delivery of elderly programme services. This seems to be inconsistent with epidemiological findings for specific disorders of a positive, exponential relationship between age and incidence or prevalence, as with the dementing illnesses, osteoporosis, and hip fractures. We may be too ready to generalise these "tidy" age relationships to other or to all disorders in late life, particularly given the flatter relationships between age (after say 55 years) and cardiovascular and cerebrovascular disorders. But the main reason why the age structure in local elderly populations is a poor indicator of domiciliary health service need and provision is differential survival. The social groups and local populations of older people with high mortality and morbidity have, by that very fact, a relatively young age structure, while more advantaged groups with low mortality and morbidity risks achieve the highest mean ages. The counter-intuitive result is that when comparing older populations in different areas, it is sometimes the case that the youngest have the highest per capita morbidity and service need.

The cooperation of the four community health and social service trusts has been vital for enabling access to operational dat through the SOSCARE database. The four CHSSTs are North $\&$ West Belfast, South \& East Belfast, Down and Lisburn, and North Down and Ards. Small area census data were accessed through the University of Manchester Computing Centre. Funding: this analysis derives from the Northern Ireland age
and deprivation project (NIDAGE) commissioned by the Personal Social Services Directorate of the Eastern Health and Social Services Board, Belfast.

Conflicts of interest: none.

1 Northern Ireland Economic Council. Public expenditure priorities: health and personal social services. Report 31. Belfast: Northern Ireland Economic Council, 1982

2 Northern Ireland Economic Council. The reform of health and social care in Northern Ireland: an introduction to the economic

issues. Belfast: Northern Ireland Economic Council, 1994 .
3 Warnes AM, ed. Age, deprivation and needs for health and Warnes AM, ed. Age, deprivation and needs for health and
social services among elderly people. Belfast: Eastern Health social services among elderly people.
and Social Services Board, 1995.

4 Census Office for Northern Ireland, The Northern Ireland Census Office for Northern Ireland, The Northern Ireland
census 1991: small area statistics, user guide 1, introductory

5 Townsend P. Deprivation. F Social Policy 1987;16:125-46.

6 Marmot MG, Shipley MJ, Rose G. Inequalities in death specific explanations of a general pattern? Lancet $1984 ; \mathbf{i}$ 1003-6. 
7 Pamuk E. Social class inequality in mortality from 1921 to 1972 in England and Wales. Population Studies, 1985;39:1731.

8 Power C. Health and social inequality in Europe. BMf 1994;308: 1153-6.

Whitehead M. The health divide: inequalities in health. London: Health Education Council, 1987.

10 Wilkinson RG. Divided we fall: the poor pay the price of increased social inequality with their health. BMF 1994,308:1113-4.

1 Warnes AM. Elderly people driving cars: issues and prospects. In Morgan K, ed. Gerontology: responding to an ageing population. London: Jessica Kingsley, 1992;14-32.
12 Norusis MJ. SPSS for Windows. Base system users' guide. Release 6.0. Chicago: SPSS Inc, 1993.

13 Wolf DA. Changes in the living arrangements of olde women: an international study. The Gerontologist 1995;35: 724-31

14 Warnes AM, Ford R. Migration and family care. In: Allen I, Perkins $\mathrm{E}$, eds. The future of family care. London: HMSO, 1995;65-92.

15 Warnes AM, Peters D, Armstrong GK. Age, deprivation and limiting long term illness among elderly people in south Yorkshire and Northern Ireland. Proceedings of the Limiting Yong Term Illness Conference. Liverpool Medical Institution, May 17, 1995.

.

